\title{
Predictors of Tobacco Use among Youth in India: GATS 2009- 2010 Survey
}

\author{
Shailja Sharma ${ }^{1}$, Mitasha Singh ${ }^{1}$, Pranay Lal ${ }^{2}$, Sonu Goel ${ }^{3 *}$
}

\begin{abstract}
Background: Early initiation of smoking and chewing of diverse forms of tobacco among youth in India is a significant driver for tobacco epidemic in India. Several socio-demographic factors are predictors of tobacco use in populations, especially among youth. Interventions which address these socio-demographic factors can help policy makers to curb new initiations and avert morbidity and mortality due to tobacco use. Objective: To study the various sociodemographic variables associated with tobacco use among youth in India. Materials and Methods: Secondary analysis of data from the Global Adult Tobacco Survey-India 2009-10 for the age group of 15-24 years was performed and predictors of smoking and smokeless tobacco were analyzed using data on occupation, education, and other sociodemographic factors. Results: In India there are a total of 51.3 million (22.1\%) youth (15-24 years) tobacco users. Of these 35.1 million consumes chewable tobacco $(\mathbf{1 5 . 1 \%}), \mathbf{1 6 . 2}$ million smoke (7\%) and 1.6 million are dual users (3.1\%). Males, urban, less educated, un-employed and those belonging to middle class preferred smoking over chewing; whereas, females, rural, students and those belonging to low socio-economic class are predictors of smokeless tobacco use. The major determinants of dual users are male sex, poor socio-economic strata and student class. The overall tobacco use was higher among males, rural populations, lower socioeconomic strata and un-employed class. Conclusions:_India's youth is more susceptible to the tobacco addiction, especially of smokeless tobacco. Youth from rural India especially students, girls and those from poor socio-economic strata prefer to use smokeless tobacco products whereas urban, male and those less educated prefer smoking tobacco products. More population-based and region-focused research is needed to understand initiation patterns into tobacco use among youth so as to inform policymakers to devise new policy measures to curb the growing epidemic.
\end{abstract}

Keywords: Predictors - socioeconomic factors - youth - GATS - India

Asian Pac J Cancer Prev, 16 (17), 7535-7540

\section{Introduction}

Tobacco use is a major cause of preventable cause of death and disease worldwide has been known for decades (WHO, 2008). Despite various measures taken by the Indian government, the efforts to discourage tobacco use have been mixed. Globally it has been well understood that early youth initiation drives the tobacco epidemic (CDC report of the surgeon general. preventing tobacco use among youth and young adults, 2012). According to the Global Adult Tobacco Survey 2009-2010, youth initiation of tobacco products is varied across the country, ranging from 20.4 years in Himachal Pradesh to 14.9 years in Chhattisgarh (smoked) and 20.9 years in Himachal Pradesh to 16.2 years in Chhattisgarh (smokeless), with mean age of initiation at 17.8 years (Global Adult Tobacco Survey 2009-2010). The Global Youth Tobacco Survey presents an even more grim picture where $14.6 \%$ school going students aged $13-15$ years currently use a tobacco product and another $15.5 \%$ of never smokers are likely to initiate smoking next year (Global Youth Tobacco Survey, 2006). Recent research provides several reasons for early initiation of tobacco use among youth, and perhaps the most important factor is that tobacco products remain highly affordable and accessible in India (John, 2010). Although there have been significant advances in tobacco control, the overall national implementation of tobacco control legislation across India have been mixed and sub-optimal. Rules that govern smokefree public places has perhaps made the greatest advancement in different jurisdictions in India, yet its compliance been variable (Tripathy et al., 2013; Goel et al., 2014; Kumar et al., 2014). Point of sale advertising is aggressively used by the tobacco industry to promote their products, which induces youth to initiate tobacco consumption at an early age (Goel et al., 2014).

The reasons for the youth to take up tobacco as a habit are multifactorial. Their adventurous nature and 
curiosity, coupled with various socio demographic factors are probably the most important reason for the younger generation to make these wrong choices (CDC Report of the Surgeon General. Preventing Tobacco Use Among Youth and Young Adults, 2012). The aggressive efforts of the tobacco companies to recruit fresh consumers specifically target the younger population (Glynn et al., 2003). The earlier the initiation of tobacco use the harder is the addiction to nicotine and thus difficult to leave this ill habit. Globally about 82000 to 99000 young people start smoking daily (Prokhov et al., 2006).

The patterns and predictors of tobacco use in any form have been studied in countries with different settings and cultural background like Pakistan, Nepal, Thailand, Malaysia and Vietnam. (Hammond et al., 2008; Phong et al., 2008; Binu et al., 2010; Dhanani et al., 2010). Most of them have focussed their research on smoking patterns. Smokeless form and dual form of use have been less studied. Also there is limited research on the use of tobacco among youth in the age group of 15 to 24 years in India (Lal et al., 2012). With more than 5500 new adolescent tobacco users being added everyday in India, about 2 million young people get addicted each year (Chadda et al., 2002). This paper highlights the role of various socio-economic factors responsible for the use of tobacco among the youth.

\section{Materials and Methods}

\section{Study design}

We used the disaggregated data from the Global Adult Tobacco Survey that is available in public domain (gatsindia@iips.net.) (Global Adult Tobacco Survey, India 2009-10). The Global Adult Tobacco Survey- India released in 2010 is a nationally representative survey which covered 69926 household and collated information on key tobacco control indicators and assists countries in the formulation, tracking and implementation of effective tobacco control interventions. (IIPS, 2010)

\section{Data variables and analysis}

We used this data to find an association between use of tobacco among youth (15-24 years) which was the major dependent variable and gender, education, occupation, wealth index and place of residence (independent variables).The main objective was to study the risk factors(predictors) for tobacco use among youth in India. The questions taken in to consideration were: Do you currently smoke? (B01): All daily or non daily smokers were considered as users. Do you currently use smokeless tobacco? (C01): Here too daily and less than daily users were considered tobacco consumers. The wealth index was derived from the variables that captured possession of assets by households. To assign a wealth status to each household, we used standard assets based approach. GATS-India dataset contains information for number of items possessed by a household against a list of items. This list includes items like washing machine, refrigerator, vehicle etc. We performed 'Principal Component Analysis' (PCA) to generate a wealth index score for each household on the basis of their possession of assets. First component or principal component explaining maximum variability in the data was considered to assign a score to household. As the wealth score generated using PCA was normalised score, we divided the number of households into five quintiles representing their wealth status i.e. from poorest (with minimum score) to richest (with highest score).The score for the poorest and the poor was combined under the heading of 'poor', and the rich and the richest were combined as 'rich'.

Epi Info 7 was used to carry out the statistical analysis in the study. Proportion of youth consuming all forms of tobacco was calculated. Chi square test was used to test the association between predictors and tobacco use. $\mathrm{P}$ value

Table 1. Socio-demographic profile of youth tobacco users from GATS, India 2009-10.

\begin{tabular}{|c|c|c|c|c|}
\hline Variables $*$ & $\begin{array}{l}\text { Total youth } \\
\mathrm{N}(\%)\end{array}$ & $\begin{array}{l}\text { Smokers } \\
\mathrm{N}(\%)\end{array}$ & $\begin{array}{c}\text { Smokeless tobacco } \\
\text { users N }(\%)\end{array}$ & $\begin{array}{c}\text { Dual Users } \\
\mathrm{N}(\%)\end{array}$ \\
\hline \multicolumn{5}{|l|}{$\overline{\text { GENDER }}$} \\
\hline Male & $6209(46.11)$ & $879(14.2)$ & $1313(21.2)$ & $382(6.2)$ \\
\hline Female & $7254(53.8)$ & $61(0.80)$ & $716(9.9)$ & $29(0.40)$ \\
\hline \multicolumn{5}{|l|}{ RESIDENCE } \\
\hline Rural & $8182(60.8)$ & $605(7.4)$ & 1437(17.6) & $282(3.5)$ \\
\hline Urban & $5281(39.2)$ & $335(6.3)$ & $592(11.2)$ & $129(2.4)$ \\
\hline \multicolumn{5}{|l|}{ EDUCATION } \\
\hline No formal education & 1374(10.2) & $110(8.0)$ & $328(23.9)$ & $57(4.2)$ \\
\hline Primary incomplete & $1137(8.4)$ & $135(11.9)$ & $294(25.9)$ & $67(5.9)$ \\
\hline Primary but secondary incomplete & 1604(11.9) & $363(22.6)$ & $854(53.2)$ & $168(10.5)$ \\
\hline Secondary and higher secondary & $3235(24.02)$ & 273(8.4) & $477(14.7)$ & $104(3.2)$ \\
\hline Graduation and above & $2587(19.2)$ & $56(2.2)$ & $70(2.7)$ & $13(0.5)$ \\
\hline \multicolumn{5}{|l|}{ OCCUPATION } \\
\hline Govt.employee/non govt & 1913(14.2) & 221(11.6) & $475(24.8)$ & $112(5.9)$ \\
\hline Self Employed & $2229(16.5)$ & $367(16.5)$ & $620(27.8)$ & $147(6.6)$ \\
\hline Student & $5359(39.8)$ & $228(4.3)$ & $422(7.9)$ & $83(1.6)$ \\
\hline Home maker & $3488(25.9)$ & $53(1.5)$ & $386(11.1)$ & $24(0.7)$ \\
\hline Unemployed & $467(3.5)$ & $70(15.0)$ & $123(26.3)$ & $44(9.4)$ \\
\hline \multicolumn{5}{|l|}{ WEALTH INDEX } \\
\hline Poor class & 2541(18.9) & $278(10.9)$ & $704(27.7)$ & $132(5.2)$ \\
\hline Middle class & $5683(42.2)$ & $192(3.4)$ & $530(9.3)$ & $184(3.2)$ \\
\hline Rich class & $5169(38.4)$ & $463(9.0)$ & $794(15.4)$ & $94(1.8)$ \\
\hline
\end{tabular}


Table 2. Association of Predictors with U se of Smoke, Smokeless and Dual Forms of Tobacco among the Youth GATS, India 2009-2010

\begin{tabular}{|c|c|c|c|c|c|}
\hline \multirow{2}{*}{\multicolumn{2}{|c|}{$\begin{array}{c}\text { Smoker } \\
\text { Unadjusted OR Adjusted OR } \\
(95 \% \mathrm{CI})\end{array}$}} & \multicolumn{2}{|c|}{ Smokeless Tobacco users } & \multicolumn{2}{|c|}{ Dual users } \\
\hline & & $\begin{array}{l}\text { Unadjusted OR } \\
(95 \% \mathrm{CI})\end{array}$ & $\begin{array}{l}\text { Adjusted OR } \\
(95 \% \mathrm{CI})\end{array}$ & $\begin{array}{l}\text { Unadjusted OR } \\
\qquad(95 \% \mathrm{CI})\end{array}$ & $\begin{array}{l}\text { Adjusted OR } \\
(95 \% \mathrm{CI})\end{array}$ \\
\hline \multicolumn{6}{|l|}{$\overline{\mathrm{AGE}}$} \\
\hline $15-24 \quad 0.32(0.29-0.34)$ & $0.32(0.29-0.34)$ & $0.49(0.47-0.52)$ & $0.49(0.47-0.52)$ & $0.45(0.40-0.49)$ & $0.45(0.40-0.49)$ \\
\hline $0.00 *$ & $0.00 *$ & $0.00 *$ & $0.00 *$ & $0.00 *$ & $0.00 *$ \\
\hline \multicolumn{2}{|l|}{25 and above Reference } & \multicolumn{2}{|l|}{ Reference } & \multicolumn{2}{|l|}{ Reference } \\
\hline \multicolumn{6}{|l|}{ GENDER } \\
\hline \multirow{2}{*}{$\begin{array}{l}19.45(0.29-0.34) \\
0.00 *\end{array}$} & $24.99(17.62-35.43)$ & \multirow{2}{*}{$\begin{array}{l}2.45(2.22-2.70) \\
0.00 *\end{array}$} & \multirow{2}{*}{$\begin{array}{l}0.41(0.36-0.47) \\
0.00 *\end{array}$} & \multicolumn{2}{|c|}{$16.33(11.18-23.86) \quad 0.05(0.03-0.08)$} \\
\hline & $0.00 *$ & & & $0.00 *$ & \multirow{2}{*}{$0.00 *$} \\
\hline Female Reference & & Reference & & Reference & \\
\hline \multicolumn{6}{|l|}{ RESIDENCE } \\
\hline \multirow{2}{*}{$\begin{array}{c}\text { Urban } 0.85(0.74-0.98) \\
0.012^{*}\end{array}$} & $1.06(0.91-1.23)$ & $0.59(0.53-0.66)$ & $0.70(0.63-0.79)$ & $0.70(0.57-0.87)$ & $0.81(0.65-1.01)$ \\
\hline & $0.487 *$ & $0.00 *$ & $0.00 *$ & $0.001 *$ & $0.055^{*}$ \\
\hline \multirow{2}{*}{\multicolumn{2}{|c|}{$\begin{array}{l}\text { Rural } \\
\text { EDUCATION }\end{array}$}} & \multicolumn{2}{|l|}{ Reference } & \multicolumn{2}{|l|}{ Reference } \\
\hline & & & & & \\
\hline Graduation and above & & & & & \\
\hline $0.52(0.38-0.73)$ & $0.45(0.31-0.64)$ & $0.18(0.14-0.24)$ & $4.36(3.28-5.81)$ & $0.24(0.13-0.43)$ & $4.59(2.44-8.66)$ \\
\hline $0.00 *$ & $0.00 *$ & $0.00 *$ & $0.00 *$ & $0.00 *$ & $0.00 *$ \\
\hline Secondary and higher sec & condary & & & & \\
\hline $0.69(0.55-0.87)$ & $0.57(0.43-0.74)$ & $0.35(0.30-0.41)$ & $2.35(1.97-2.80)$ & $0.51(0.37-0.71)$ & $.24(1.55-3.22)$ \\
\hline $0.002 *$ & $0.00 *$ & $0.00 *$ & $0.00 *$ & $0.00 *$ & $0.00 *$ \\
\hline Primary but secondary in & complete & & & & \\
\hline $0.93(0.75-1.16)$ & $0.63(0.49-0.81)$ & $0.68(0.59-0.79)$ & $1.51(1.29-1.77)$ & $0.83(0.61-1.13)$ & $1.67(1.21-2.32)$ \\
\hline $0.53 *$ & $0.001 *$ & $0.00 *$ & $0.00 *$ & $0.24 *$ & $0.002 *$ \\
\hline Primary incomplete & & & & & \\
\hline $1.55(1.19-2.02)$ & $0.94(0.69-1.26)$ & $1.11(0.93-1.33)$ & $1.11(0.92-1.34)$ & $1.45(1.01-2.08)$ & $1.12(0.76-1.63)$ \\
\hline $0.001 *$ & $0.659 * 0.25 *$ & $0.30 *$ & $0.045 *$ & $0.569 *$ & \\
\hline No formal schooling Ret & ference & Reference & & Reference & \\
\hline OCCUPATION & & & & & \\
\hline Govt./Non govt employe & & & & & \\
\hline $0.75(0.56-1.00)$ & $0.75(0.55-1.02)$ & $0.94(0.74-1.18)$ & $1.01(0.79-1.28)$ & $0.61(0.42-0.87)$ & $1.64(1.13-2.40)$ \\
\hline $0.05 *$ & $0.064 *$ & $0.58 *$ & $0.97 *$ & $0.006 *$ & $0.006 *$ \\
\hline Self employed & & & & & \\
\hline $1.12(0.85-1.48)$ & $0.99(0.75-1.34)$ & $1.08(0.86-1.35)$ & $1.02(0.81-1.29)$ & $0.68(0.48-0.97)$ & $1.74(1.20-2.51)$ \\
\hline $0.43 *$ & $0.995 *$ & $0.52 *$ & $0.86^{*}$ & $0.03 *$ & $0.003^{*}$ \\
\hline Student & & & & & \\
\hline $0.25(0.19-0.34)$ & $0.36(0.27-0.49)$ & $0.24(0.19-0.30)$ & $2.77(2.18-3.52)$ & $0.15(0.10-0.22)$ & $4.13(2.70-6.01)$ \\
\hline $0.00 *$ & $0.00 *$ & $0.00 *$ & $0.00 *$ & $0.00 *$ & $0.00 *$ \\
\hline Homemaker & & & & & \\
\hline $0.09(0.06-0.13)$ & $0.91(0.57-1.44)$ & $0.35(0.28-0.44)$ & $1.65(1.28-2.14)$ & $0.07(0.04-0.11)$ & $1.84(0.93-3.26)$ \\
\hline $0.00 *$ & $0.68 *$ & $0.00 *$ & $0.00 *$ & $0.00 *$ & $0.084 *$ \\
\hline Unemployed & & Reference & & Reference & \\
\hline WEALTH INDEX & & & & & \\
\hline Poor class & & & & & \\
\hline $0.52(0.45-0.61)$ & $0.54(0.44-0.66)$ & $1.28(1.15-1.43)$ & 2.01(1.76-2.29) & $1.55(1.24-1.95)$ & $1.73(1.30-2.28)$ \\
\hline $0.00 *$ & $0.00 *$ & $0.00 *$ & $0.00 *$ & $0.00 *$ & $0.00 *$ \\
\hline Rich class & & & & & \\
\hline $0.83(0.69-0.99)$ & $1.18(0.98-1.43)$ & $0.69(0.61-0.78)$ & $1.46(1.28-1.67)$ & $0.96(0.75-1.24)$ & $1.02(0.78-1.33)$ \\
\hline $0.038 *$ & $0.084 *$ & $0.00 *$ & $0.00 *$ & $0.757 *$ & $0.897 *$ \\
\hline Middle class & lce & Reference & & Reference & \\
\hline
\end{tabular}

$<0.05$ was considered significant. Logistic regression analysis was used to calculate the relationship between tobacco use among youth and various independent variables. Adjusted odds ratios with $95 \%$ confidence intervals was calculated.

\section{Ethics}

The study was exempted from ethics review by the chairperson of the Ethics Advisory Group of International Union against Tuberculosis and Lung Disease, as it was a secondary analysis of existing dataset without involvement of any direct interaction with human participants.

\section{Results}

The total population interviewed in GATS India -2010 was 69,926 . Of these the youth population between 15- 24 years was $13463(19.3 \%)$. The total number of tobacco users (smokers and smokeless) among the youth were $2969(22.1 \%)$ whereas those who did not use tobacco in any form were 10494 (77.9\%). Among tobacco users, there were $411(3.1 \%)$ dual users (both smoked and smokeless form). Use of smokeless tobacco was found to be higher $(\mathrm{n}=2029,15.1 \%)$ as compared to smoked form $(n=940,7 \%)$. Male gender being a prominent predictor of tobacco use, with $35.3 \%$ of total males was tobacco 
Table 3. Association of predictors with overall tobacco use among the youth GATS, India 2009-10

\begin{tabular}{|c|c|c|}
\hline Predictors & \multicolumn{2}{|c|}{ Tobacco use } \\
\hline & Unadjusted OR (95\% CI) & Adjusted OR (95\% CI) \\
\hline \multicolumn{3}{|l|}{$\overline{\mathrm{AGE}}$} \\
\hline \multicolumn{3}{|c|}{ 15-24years } \\
\hline \multirow{2}{*}{\multicolumn{2}{|c|}{$\begin{array}{l}0.37(0.35-0.38) \\
0.00^{*}\end{array}$}} & $0.37(0.35-0.38)$ \\
\hline & & $0.00 *$ \\
\hline \multicolumn{2}{|c|}{25 and above reference } & reference \\
\hline \multicolumn{3}{|c|}{ GENDER } \\
\hline \multirow[t]{2}{*}{ Male } & $3.56(3.26-3.93)$ & $3.51(3.10-3.98)$ \\
\hline & $0.00 *$ & $0.00 *$ \\
\hline Female & reference & reference \\
\hline \multicolumn{3}{|l|}{ Residence } \\
\hline \multirow[t]{2}{*}{ Urban } & $0.65(0.59-0.71)$ & $0.80(0.72-0.88)$ \\
\hline & $0.00^{*}$ & $0.00 *$ \\
\hline Rural & reference & reference \\
\hline \multicolumn{3}{|c|}{ EDUCATION } \\
\hline \multicolumn{3}{|c|}{ Graduation and above } \\
\hline & $0.25(0.20-0.31)$ & $0.36(0.27-0.46)$ \\
\hline & $0.00^{*}$ & $0.00 *$ \\
\hline \multicolumn{3}{|c|}{ Secondary and higher secondary } \\
\hline & $0.40(0.35-0.47)$ & $0.53(0.45-0.63$ \\
\hline & $0.00^{*}$ & $0.00 *$ \\
\hline \multicolumn{3}{|c|}{ Primary but secondary incomplete } \\
\hline & $0.72(0.63-0.83)$ & $0.72(0.61-0.84)$ \\
\hline & $0.00^{*}$ & $0.00 *$ \\
\hline \multicolumn{3}{|c|}{ Primary incomplete } \\
\hline & $1.22(1.03-1.45)$ & $1.01(0.84-1.22)$ \\
\hline & $0.03 *$ & 0.90 \\
\hline no form & schooling reference & reference \\
\hline \multicolumn{3}{|c|}{ OCCUPATION } \\
\hline \multicolumn{3}{|c|}{ Gov/Non govt employee } \\
\hline & $0.96(0.76-1.20)$ & $0.97(0.76-1.23)$ \\
\hline & 0.72 & 0.79 \\
\hline \multicolumn{3}{|c|}{ Self employed } \\
\hline & $1.30(1.04-1.62)$ & $1.15(0.91-1.46)$ \\
\hline & $0.02 *$ & 0.24 \\
\hline \multicolumn{3}{|l|}{ Student } \\
\hline & $0.25(0.20-0.32)$ & $0.38(0.30-0.49)$ \\
\hline & $0.00^{*}$ & $0.00 *$ \\
\hline \multicolumn{3}{|c|}{ Homemaker } \\
\hline & $0.29(0.23-0.37)$ & $0.64(0.50-0.83)$ \\
\hline & $0.00 *$ & $0.001 *$ \\
\hline Unempl & ed reference & reference \\
\hline \multicolumn{3}{|c|}{ WEALTH INDEX } \\
\hline \multirow[t]{2}{*}{ Poor } & $1.63(1.45-1.83)$ & $1.32(1.16-1.50)$ \\
\hline & $0.00 *$ & $0.00 *$ \\
\hline Rich & $0.68(0.60-0.77)$ & $0.93(0.81-1.07)$ \\
\hline & $0.00^{*}$ & 0.31 \\
\hline Middle & reference & reference \\
\hline
\end{tabular}

users as compared to $10.7 \%$ of females. $29.5 \%$ of youth residing in the rural areas were tobacco users as compared to $17.5 \%$ in the urban areas. Poverty and poor education were also found to be key predictors of tobacco use. The use of tobacco was more among youth who had received education between primary and secondary class $(75.8 \%)$ or till primary school $(37.7 \%)$ as compared to those who had completed their graduation $(4.8 \%)$. Similarly, the poor section of society (38.6\%) was higher on tobacco use as compared to rich class $(24.3 \%)$ and middle class $(12.7 \%)$.Maximum use of tobacco was seen among youth who were unemployed (41.3\%), self-employed (44.2\%) or employed in government/ non-government jobs $(36.4 \%)$ as compared to students (12\%). The demographic details of the youth population who are users of tobacco are given in Table 1.
Smoking among youth was significantly higher in males (OR 24.99, 95\% CI 17.62-35.43) showing male gender as being an important predictor of smoked tobacco consumption. The smoking habit was significantly. Smoking decreased with increasing education, highlighting lesser education as a key predictor for increased use of tobacco. There was almost $40 \%$ less smoking among youths pursuing secondary and higher secondary education (OR $0.57,95 \%$ CI $0.43-0.74$ ) and 55\% less in those pursuing graduation and above (OR $0.45,95 \% \mathrm{CI}$ 0.31-0.64) as compared to youth smokers who had no formal schooling. In addition, significantly lower smoking was observed among the poor class (OR $0.54,95 \% \mathrm{CI}$ $0.44-0.66)$ as compared to the middle and the rich class.

The use of smokeless forms of tobacco was significantly less among male youth as compared to their counterparts (OR 0.41 , 95\% CI 0.36-0.47), which clearly indicates that female gender is a prominent predictor of smokeless tobacco use. The rural youth (OR $0.70,95 \%$ CI 0.63 0.79 ) consumed $30 \%$ more smokeless tobacco than their urban counterparts. While studying the possible association with smokeless tobacco use with education a positive association was observed wherein youth pursuing graduation and higher degrees were the highest users (OR 4.36, 95\% CI 3.28-5.81) as compared to those with no formal schooling. The use of smokeless tobacco was highest among students (OR 2.77, 95\% CI 2.18-3.52) as compared to youth in other professions. The use of smokeless tobacco was found in all the socioeconomic classes derived from the wealth index, however maximum use was seen among the poor (OR 2.01, 95\% CI 1.76-2.29) followed by the rich (OR 1.46, 95\% CI 1.28-1.67).

Dual users were $20 \%$ more in the rural area and majority of them were from the poor socio economic class (OR 1.73, 95\% CI 1.30-2.28). Dual tobacco use was significantly more popular among students (OR 4.13, 95\% CI 2.70-6.01) and graduates and above (OR 4.59, 95\% CI 2.44-8) as compared to other occupation and profession respectively. The regression analysis for measuring the association of predictors with smokers, smokeless and dual use is shown in Table 2.

The regression analysis in Table 3 shows the predictors of any type of tobacco use among the youth. Any type of tobacco use was observed to be more in male youth (OR 3.51, 95\% CI 3.10-3.98) as compared to female counterparts. Tobacco use was positively associated with those who were self- employed (OR $1.15,95 \%$ CI 0.91-1.46) as compared to other professions; however the association was non- significant. Among all socioeconomic classes tobacco use was significantly higher among the poor class (OR 1.32, 95\% CI 1.16-1.50)

\section{Discussion}

Death due to tobacco use is expected to increase dramatically in the coming decades. Mortality from smoking alone will double from 2030 in India given the large persistent cohort of lifelong smokers in India (Lal et al., 2012). Majority of these deaths would occur during the productive years of life due to the addiction acquired 
during youth (Reddy et al., 2005). The analyses of data from GATS-2010 reveal that almost $22.1 \%$ (51.3 million) youth smoke, chew or use both forms of tobacco products.

The current survey showed a significantly higher use of tobacco smokers belong to poor socio-economic and less educated strata, which remains one of the strongest predictors of tobacco use, as across the world. In India, tobacco consumption is highest among youth who have received formal education till the primary level. This could probably be due to lack of knowledge about the hazards of tobacco use. Several studies while assessing the relation between use of tobacco and education have reported decrease in the use of tobacco with increase in education (Rani et al., 2003). Similar to situation in India, a study among Nepali youth showed that smoked tobacco was associated more with middle and higher income groups than the low income (Binu et al., 2010). Higher use of smokeless form of tobacco was seen in the students and overall tobacco use was more among un-employed or self- employed youth. The spirit of adventure and experimentation among the students could perhaps be one of the causes for tobacco use among the students. These findings of increased tobacco use among people in lower socio-economic strata are in accordance with several other studies (Gupta et al., 1996). Expenditure on essential commodities is sometimes compromised to afford tobacco products in families of poor socio-economic strata, which not only leads to impoverishment, but also increased morbidity and mortality (Thakur et al., 2013).

Gender was also an important predictor of smoking among the Nepali youth with males ten times more likely to be smokers than females (Binu et al., 2010). This corresponds to the findings of other studies where proportion of female smokers was lower than males (Palipudi et al., 2012) and in fact some studies found that there were no female smokers at all in their sample (Singh et al., 2003; Nichter et al., 2004; Kumar et al., 2005; Sharma et al., 2006; Chandrashekhar et al., 2008; Siziya et al., 2008). This is not necessarily the same in all parts of the world as a study in young adults in Canada showed that females were more likely to be daily smokers as compared to males though the number of cigarettes they smoked was fewer (Hammond D, 2005). Alarmingly there is an increasing trend of smoking among women as compared to male counterparts in India (Goel et al., 2014, Roy P et al., 2015). The challenge for policymakers while designing youth-focused interventions is the long windows of vulnerability. The tobacco industry is clearly aware of this and exploits these to ensure that it creates a cohort of tobacco addicts every year as youth initiations translate into profits for tobacco companies. We conclude that efforts directed towards discouraging tobacco use initiation, among the young population should be an important part of all policies directed towards tobacco control. Creating awareness about the dangers of tobacco use among the younger generation would reduce the large number of new tobacco users adding on to the already existing user population. The raising of age of purchase of tobacco products at Point of Sale (POS) from existing 18 years to 21 years is also a useful strategy to curb initiation of tobacco products (Lal et al., 2012). Further, tobacco control related issues should be integrated in curricula of public health students, so as to build their capacity for influencing policy makers on this key issue (Yadav et al., 2014). Youth are extremely sensitive to price, and if taxes are raised above inflationary trends and strongly administered, tobacco products will become less affordable (World Bank, 1999). Pack warnings, ban of tobacco advertising and stronger implementation of laws which reduce access of tobacco products in youth, can additionally help reduce current initiation and future prevalence of tobacco use. Together such efforts would be more fruitful in curbing this growing menace than spending large amount of scarce resources on de-addiction and treatment of diseases due to tobacco use.

\section{References}

Report of the Surgeon General. Preventing Tobacco Use among Youth and Young Adults (2012). Centres for Disease Control, Washington DC, United States.

A Yadav, S Goel, VL Sharma (2014). Integration of tobacco control in masters of public health curricula of India. Asian Pac J Cancer Prev, 15, 5611-5.

Binu VS, Subba SH, Menezes RG, et al (2010). Smoking among nepali youth - prevalence and predictors. Asian Pac J Cancer Prev, 11, 221-6.

Chadda RK, Sengupta SN (2002). Tobacco use among indian adolescents. Tobacco Induced Dis, 1, 111-19.

Chandrashekhar TS, Kishore PV, Paudel J, Menezes RG (2008). Prevalence and correlates of tobacco use amongst junior collegiates in twin cities of western Nepal: A cross-sectional, questionnaire-based survey. BMC Public Health, 8, 97.

Dhanani R, Jafferani A, Bhulani N, et al (2010). Predictors of oral tobacco use among young adult patients visiting family medicine clinics in Karachi, Pakistan. Asian Pac J Cancer Prev, 11, 43-7.

District Level Household Survey-3, India (2007-2008). International institute for population sciences (IIPS), 2010. Mumbai, India.

Gupta PC (1996). Survey of socio demographic characteristics of tobacco use among 99598 individuals in Bombay, India using handheld computers. Tobacco control, 5, 114-120.

Glynn TJ, Mills SL (2003). Youth tobacco use research in the USA: progress and challenges. Tobacco Control, 12, 1-2.

Global Adult Tobacco Survey, India (2009-10). International institute for population sciences (iips), 2010. ministry of health and family welfare, government of India, New Delhi.

Goel S, Kumar R, Lal P, et al (2014). How compliant are tobacco vendors to india's tobacco control legislation on ban of advertisments at point of sale? a three jurisdictions review. Asian Pac J Cancer Prev, 15, 10637-42.

Goel S, Ravindra K, Singh RJ, Sharma D (2014). Effective smoke-free policies in achieving a high level of compliance with smoke-free law: experiences from a district of North India. Tob Control, 23, 291-4.

Goel S, Tripathy JP, Singh RJ, Lal P (2014). Smoking trends among women in India: Analysis of nationally representative surveys (1993-2009). South Asian J Cancer, 3, 200-2.

Hammond D (2005). Smoking behaviour among young adults: beyond youth prevention. Tobacco Control, 14, 181-5.

Hammond D, Kin F, Prohmmo A, et al (2008). Patterns of smoking among adolescents in malaysia and thailand: findings from the international tobacco control southeast asia survey. Asia Pac J Public Health, 20, 193-203 


\section{Shailja Sharma et al}

International Institute for Population Sciences (IIPS), 2010. district level household and facility survey (DLHS-3), 20072008: India. Mumbai: IIPS.

John RM, Rao RK, Rao MG, et al, (2010). The economics of tobacco and tobacco taxation in india. international union against tuberculosis and lung disease, Paris.

Kumar R, Goel S, Harries AD, et al (2014). How good is compliance with smoke-free legislation in India? Results of 38 subnational surveys. Int Health, 6, 189-95.

Lal P, Wilson NC, Srivastava S, Millett C (2012). Should the legal age for the purchase of tobacco be increased to 21 years? Global Heart, 7, 183-7.

Lal PG, Wilson NC, Gupta PC (2012). Attributable deaths from smoking in the last 100 years in India. Current Science, 103, 1085-90.

Nichter M, Nichter M, Sickle DV (2004). Popular perceptions of tobacco products and patterns of use among male college students in India. Social Sci Med, 59, 415-31.

Phong DN (2008). Smoking among vietnamese medical students: prevalence, costs, and predictors. Asia Pac J Public Health, 20, 16-24.

Pradeep Kumar AS, Mohan S, Gopalakrishnan, et al (2005). Tobacco use in Kerala: findings from three recent studies. Natl Med J India, 18, 148-53

Prokhov AV, Winickoff JP, Ahluwalia JS, et al (2006). Youth Tobacco use: A Global perspective for child health care clinicians. Paediatr, 118, 890-903.

Palipudi KM, Gupta PC, Sinha DN, et al (2012). Social determinants of health and tobacco use in thirteen low \& middle income countries: evidence from global adult tobacco survey, PLoS One, 7, 1-8.

Rani M, Bonu S, Jha P, Nguyen SN, Jamjoum L (2003). Tobacco use in India: prevalence and predictors of smoking and chewing in a national cross sectional household survey. Tobacco Control, 12, 1-8.

Reddy KS, Arora M (2005). Tobacco Use among Children in India: A Burgeoning. Indian Paediatr, 42, 757-61.

Report of Global Adult Tobacco Survey (2009-2010). International Institute of Population Sciences. Ministry of Health \& Family Welfare, Government of India.

Report of Global Youth Tobacco Survey (2006). International Institute of Population Sciences. Ministry of Health \& Family Welfare, Government of India.

Roy P, Goel S (2015). Is female smoking rising or declining in India? South Asian J Cancer, 4, 99-100.

Shah VN, Verma PB, Tripathi CB (2005). Knowledge, attitude and practice regarding tobacoo consumption among the college students of Bhavnagar City (Gujarat). Indian J Commun Med, 30, 39-40.

Sharma N, Singh MM, Ingle GK, Jiloha RC (2006). An Epidemiological study of cigarette smoking among male college students of Delhi University. Indian J Commun Med, 31, 35 .

Singh VV, Singh Z, Banerjee A, Basannar DR (2003). Determinants of smoking habit among medical students. Med J Armed Force India, 59, 209-11.

Siziya S, Muula AS, Rudatsikira E (2008). Correlates of current cigarette smoking among school-going adolescents in punjab, india: results from the global youth tobacco survey. BMC Int Health Human Rights, 14, 1.

Thakur JS, Prinja S, Bhatnagar N, Rana S, Sinha DS, Singh P $\mathrm{K}$ (2013). Socioeconomic inequality in the prevalence of smoking and smokeless tobacco use in India. Asian Pac J Cancer Prev, 14, 6965-69

Tripathy JP, Goel S, Patro BK (2013). Compliance monitoring of prohibition of smoking (under section-4 of COTPA) at a tertiary health-care institution in a smoke-free city of India.
Lung India, 30, 312-5.

World Bank (1999). Curbing the epidemic: governments and the economics of tobacco control. World Bank publications, Washington DC.

WHO (2008). Report on the Global Tobacco Epidemic 2008, The MPOWER package. World Health Organization, Geneva. 